\title{
MARY SHELLEY, ENTRELAZAMIENTO DE ILUSTRACIÓN Y ROMANTICISMO
}

\author{
ASUNCIÓN HERRERA GUEVARA \\ Universidad de Oviedo
}

\begin{abstract}
RESUMEN: Frankenstein, la novela de Mary Shelley, es un trabajo primordial dentro de la Historia de las Ideas para encontrar los vínculos entre dos períodos centrales de la Modernidad: la llustración y el Romanticismo. Podemos hacer tanto una interpretación ilustrada de la novela como una interpretación romántica. En este trabajo mostraré cómo es posible entrelazar ideas ilustradas y románticas. Lograré mi objetivo interpretando el significado de dos ideas centrales que conforman el trabajo de Mary Shelley. Me refiero a la idea de ciencia y a la idea de «lo mujer».
\end{abstract}

PALABRAS CLAVE: ciencia; feminismo; llustración; Romanticismo.

\section{Mary Shelley, Interlacement of Enlightenment and Romanticism}

ABSTRACT: Frankenstein, the novel of Mary Shelley, is a main work for to find the links between two central periods of Modernity: Enlightenment and Romanticism. We can to do both an enlightened interpretation of the novel and a romantic interpretation. In this paper I will show how It's possible interweave enlightened and romantic ideas. I will achieve my goal by analyzing the meaning of two central ideas. Both ideas make up Mary Shelley's work. I refer to the idea of Science and Femininity.

KEY WORDS: science; feminism; Enlightenment; Romanticism.

\section{INTRODUCCIÓN}

En 1818 una joven de 21 años llamada Mary Shelley publica una de las obras más universales de la literatura, Frankenstein, o el moderno Prometeo. Novela que comenzó a escribir en el verano de 1816 con tan sólo 19 años de edad. Es cierto que la madurez física e intelectual en épocas precedentes, con otro tipo de sociedad, de cultura y de esperanza de vida, se adquiría a una edad más temprana que en la actualidad; aun así, no deja de sorprender la pericia literaria que muestra una joven mujer de la segunda década del siglo XIX a pesar de las limitaciones intelectuales que su época imponía a las mujeres.

Tal vez nos sintamos menos sorprendidos si descubrimos que esa joven era hija de dos pensadores cruciales de finales del XVIII, Mary Wollstonecraft y William Godwin. Su madre una pensadora feminista, autora de una de las obras claves del feminismo de la Ilustración, Vindicación de los derechos de la mujer; su padre un filósofo político caracterizado, por muchos, como radical y exponente de un incipiente anarquismo, con una influyente obra, Justicia política. La influencia más directa la recibirá de su padre quien falleció en 1836 nada menos que a la edad de 80 años. La influencia de su madre de haberla tuvo que ser virtual; Mary Wollstonecraft murió once días después de dar a luz a la hija de ambos, Mary Shelley.

Una joven como Mary Shelley no recibió una educación institucional profusa ni ortodoxa, evidentemente no cursó estudios universitarios, su padre la 
educó en diversas materias y lecturas, al mismo tiempo que se ayudó en tal tarea de alguna tutora e institutriz. Eso sí, la hija de Mary Wollstonecraft vivió rodeada de libros, incluidos los de su madre, y del abundante círculo intelectual que giraba en torno a su padre. Una experiencia que bien pudiera ser interesante para la joven Mary fue, sin duda, el año que pasó con la familia del disidente radical William Baxter en Escocia, más concretamente entre 1812 y 1813.

El grupo de los llamados «disidentes» era muy numeroso. Con este término se hacía referencia a los fieles protestantes que no pertenecían a la Iglesia de Inglaterra. Dentro de este espacio se generó el radicalismo político de la época. Curiosamente, Richard Price, uno de estos disidentes, ejerció una gran influencia en la vida y en la obra de la madre de Mary Shelley (además del papel tan importante que jugó la obra de Rousseau El Emilio). Richard Price fue el pastor radical que se enfrentó nada menos que al pensamiento político más conservador y potente del momento, el pensamiento de Edmund Burke.

En un contexto político y existencial nada conservador transcurrió la formación y la vida de la joven Mary Shelley. Su vida tampoco fue conservadora, todo lo contrario, su temprano enamoramiento del poeta y filósofo Percy Bysshe Shelley no fue un acontecimiento anodino. Supuso un enfrentamiento entre Mary y su padre, quien se opuso a que su hija mantuviera relaciones con un hombre casado. El espíritu rebelde de Mary la llevó a abandonar su hogar junto con su amante en 1814 con tan solo 17 años. Las cosas tampoco mejoraron para Mary Shelley tras su casamiento con el poeta, tras el suicidio de la primera mujer de éste en 1816. En el intermedio de ese período, entre 1814 y 1816, Mary Shelley quedó embarazada, perdiendo a su hija en un parto prematuro. Quisiera destacar que perdió a dos hijos más, tan sólo sobrevivió su cuarto hijo, Percy Florence Shelley. El gran amor de su juventud, Percy B. Shelley, murió tempranamente en 1822, se ahogó tras el hundimiento de su velero. A partir de entonces Mary Shelley vivió entregada a la educación de su hijo y a su obra literaria.

No entraré en más detalles sobre su biografía, sólo he querido dar una pincelada que permita comprender la carga ética, social y feminista que pudiéramos encontrar en la obra Frankenstein, o el moderno Prometeo.

\section{ILUSTRACión y Romanticismo EN EL FRANKENSTEIN}

Un primer aspecto que quisiera destacar de la obra de Mary Shelley es la yuxtaposición de dos de los movimientos más relevantes de la cultura occidental, me refiero al período ilustrado y al período romántico que abarcan, esencialmente, una parte del siglo XVIII y del XIX.

Para empezar es necesario subrayar que no ha habido nunca una sola Ilustración, como tan poco ha existido un corte real entre ambos planteamientos de ver y comprender el mundo; Ilustración y Romanticismo no son pensares contrapuestos, ni mucho menos, sino que forman una constelación en nuestra 
dialéctica de la Modernidad. Lo que llamamos período moderno no puede ser interpretado, para ser justos, sin la yuxtaposición existente entre elementos ilustrados y románticos. Por otro lado, afirmar que no ha existido una única Ilustración tampoco significa negar la existencia de un proyecto común europeo llamado Ilustración. La Sittlichkeit («lo sabido y querido por todos» o la «eticidad») de cada pueblo impone una idiosincrasia a la ilustración vivida en Francia, por poner un ejemplo, e impondrá otra a las tierras germánicas. A pesar de esto o junto a esto, nos encontramos con un momento histórico que supone nada menos que el nacimiento de las grandes naciones europeas y de concepciones ideológicas centrales que llegan hasta la actualidad y que conforman lo que podríamos denominar un plexo común filosófico.

La obra de Mary Shelley no sólo recogerá elementos ilustrados y románticos de diferentes pueblos, cada uno con su idiosincrasia, sino algo muy importante, recoge el espíritu paradójico y contradictorio con el que nace la Ilustración. Citaré un solo ejemplo: ¿acaso la obra Frankenstein, o el moderno Prometeo no está impregnada de todas las paradojas en relación a la idea de progreso? No existió una única idea de progreso en la Francia ilustrada, lo que nos encontramos es un debate sobre el progreso. Para Rousseau, por ejemplo, el progreso moral no se da a través del perfeccionamiento de las artes y de las ciencias. Esa será su diatriba fundamental desarrollada en el ensayo que presenta a la Academia de Dijon en 1750. Las artes y las ciencias, planteará Rousseau, no nos acercan más a la moralidad, todo lo contrario, nos alejan de la virtud ${ }^{1}$. El debate sobre el progreso tiene un antes y un después en el período ilustrado; pero siempre ha habido contradicciones sobre el paralelismo y el influjo que ejerce un incipiente y vertiginoso progreso científico sobre el llamado progreso moral. ¿No es evidente la lucha de Víctor Frankenstein entre su creencia en el papel emancipador de la ciencia y, al mismo tiempo, su constatación de que tal progreso científico - ejemplificado en la creación de su criatura- puede destruir a la humanidad? Volveré sobre este punto en un apartado posterior.

Retomaré una primera afirmación realizada al inicio del apartado: no ha existido una única Ilustración. Por el contrario, el movimiento ilustrado fue un movimiento plural desde su nacimiento. Solamente en la vieja Europa, podemos destacar tres potentes corrientes ilustradas con características propias. $\mathrm{Me}$ refiero, evidentemente, a la Ilustración inglesa, francesa y alemana.

La segunda afirmación, con la que inicié el apartado, me ha conducido a proclamar la constelación de elementos ilustrados y románticos en la obra de Mary Shelley. Por tanto, diversos elementos de estas ilustraciones están presentes en la obra de nuestra autora y, a su vez, sus rasgos se constelan con elementos románticos. La ciencia, la igualdad, la libertad moderna o el problema de la identidad son valores configurativos presentes en las tres ilustraciones antes mencionadas. Veamos como se constelan con elementos románticos.

1 Rousseau, J. J., Discurso sobre las ciencias y las artes. Discurso sobre la desigualdad entre los hombres, Alianza Editorial, Madrid 2012. 


\section{La CIENCIA EN El Siglo de la Ilustración y El Romanticismo}

La Ilustración inglesa fue la más temprana en nacer, allá a finales del siglo XVII. Tiene un carácter profundamente analítico y científico. Como ejemplo tomemos la figura de Thomas Hobbes. El filósofo británico protagonizó en la década de 1660 y 1670 una polémica con el filósofo natural, químico, físico e inventor, Robert Boyle, a fin de emplear una bomba para crear el vacío extrayendo el aire de un recipiente de cristal. Esta controversia que se mantuvo tanto experimental como epistolariamente es un buen ejemplo del espíritu científico que se estaba viviendo en la Inglaterra de finales del XVII. Disputas como la señalada permitieron el nacimiento de la ciencia experimental ${ }^{2}$. El propio Thomas Hobbes pretendía aplicar el método científico de análisis y síntesis al estudio filosófico y político. La ciencia moderna comienza su andadura con fuerza y será, desde sus albores, un discurso legitimador de primer orden. Aunque es cierto, y este punto es preciso remarcarlo, que en sus inicios, ciencia y filosofía van de la mano.

Uno de los rasgos centrales de esta nueva ciencia será el afán de dominar lo desconocido, en la mayoría de los casos, eso desconocido se presenta como Naturaleza. La Ilustración pretenderá racionalizar lo desconocido, con el objetivo de dominarlo. Lo desconocido nos provoca miedo y angustia, nada mejor que racionalizarlo, medirlo, cuantificarlo, en definitiva, dominarlo para que deje de provocarnos terror ${ }^{3}$.

La ciencia es un elemento omnipresente en la novela de Mary Shelley. Desde el momento en que Robert Walton recoge en su barco al viajero perdido, Víctor Frankenstein, la ciencia juega un papel crucial en la historia narrada. Víctor Frankenstein, un joven ginebrino de nacimiento y de familia distinguida, sentirá predilección por la ciencia desde una temprana edad. Así lo confiesa a Robert el propio Víctor:

La filosofía natural es el genio que ha gobernado mi destino. Deseo en mi relato, por consiguiente, establecer aquellos hechos que me condujeron a sentir predilección por esta ciencia. Cuando tenía trece años fuimos todos en viaje de placer al balneario que hay cerca de Thonon [...] allí encontré por casualidad un ejemplar de las obras de Cornelio Agripa [...] Cuando regresé a casa, mi primera preocupación fue procurarme las obras completas de ese

2 Shapin, S. y Schaffer, S., Leviathan and the Air-Pump: Hobbes, Boyle and the Experimental Life, Princeton University Press, Princeton 1985.

3 Recuérdese la obra de Adorno, T. W., y Horkheimer, M., Dialéctica de la Ilustración, Trotta, Madrid 1994. En esta obra una de las ideas recurrentes les conducirá a los autores a mostrar las contradicciones y paradojas de una dialéctica de la Ilustración que comienza en los siglos XVII y XVIII y que llega hasta nuestros días. Una Ilustración que prometía la emancipación, pero que se alía con la idea de dominio a fin de evitar el miedo a lo desconocido. Lo desconocido nos puede aniquilar, ante este miedo, la respuesta ilustrada es clara: instrumentalicemos lo que nos provoca miedo y es un peligro para nuestra supervivencia. La Naturaleza y todo lo que se equipara con ella - la mujer, el hombre de otro color de piel, el judío, etc.,- ha de ser dominado si buscamos como fin último la autoconservación. 
autor, y luego las de Paracelso y Alberto Magno [...] Cuando contaba con quince años de edad nos fuimos a vivir a la casa que teníamos en las proximidades de Belrive, y un día presenciamos una tormenta eléctrica terrible [...] pedí a mi padre encarecidamente que me explicara la naturaleza y el origen del trueno y del rayo. Me contestó con una sola palabra, «Electricidad» [...] Construyó una pequeña máquina eléctrica y llevó a cabo varios experimen$\operatorname{tos}^{4}$.

El despertar científico del joven Víctor, como se ve en este punto de la narración, contiene dos elementos, uno ilustrado, mencionado con anterioridad, y otro romántico. Por un lado, el espíritu ilustrado hace que nuestro protagonista sienta, ante el temor a lo desconocido, la naturaleza de la tormenta, un fuerte impulso de dominarla. Necesita conocer, la naturaleza y el origen del trueno, para dominar. Al mismo tiempo, podemos leer entre sus páginas una clave romántica: lo desconocido aterra pero es admirado, la reflexión de Víctor no deja lugar a dudas: «[...] los truenos retumbaron al unísono en el firmamento. Contemplaba con gran curiosidad y deleite cómo arreciaba la tormenta ${ }^{5}$. No es casual que uno de los movimientos románticos más importantes de la segunda mitad del XVIII se denomine Sturm und Drang («Tormenta e Ímpetu»). Este movimiento con fuerte sesgo literario, Goethe será uno de sus máximos exponentes, se completará con autores procedentes de otros ámbitos estéticos tales como la música y las artes plásticas. Para todo el movimiento romántico del XVIII todo lo que nos provoca terror nos puede invocar, al mismo tiempo, un sentimiento que va más allá de lo bello; la naturaleza, como afirmó Kant, puede desbordar e incluso dañar nuestra sensibilidad, y en esos casos ya no nos resultará bella, pero sí sublime. La Naturaleza, esa aterradora desconocida que no deja de fascinarnos, nos deja entrever lo sublime. En numerosos pasajes de la obra de Mary Shelley se encuentra el vínculo entre lo natural y lo sublime. Para alcanzar tal conexión la autora emplea una serie de adjetivos que nos evocan la majestuosidad de la Naturaleza:

Al día siguiente proseguimos nuestro camino en mula. A medida que ascendíamos a cotas más elevadas, el valle adquiría un magnífico y asombroso aspecto [...] el impetuoso Arve y las casas diseminadas que asomaban su perfil entre los árboles formaban un paisaje de singular belleza. Esos parajes devenían sublimes con el fondo de los imponentes Alpes (más aún lo sublime parece no pertenecer a este mundo) [...] cuyas cumbres se elevaban como si pertenecieran a otro planeta y constituyeran la morada de otra raza de seres [...] Su contemplación me había elevado en tan sublime éxtasis que el alma trascendió el mundo oscuro y se elevó en pos de la luz y la alegría. La visión de una naturaleza terrible y majestuosa siempre había conseguido imprimir un tono solemne a mis pensamientos ${ }^{6}$.

4 Shelley, M., Frankenstein, o el moderno Prometeo, Penguin Clásicos, Barcelona 2015, pp. 110-112.

5 Ibíd., p. 112. La cursiva es mía.

6 Ibíd., pp. 178, 181. La cursiva es mía. 
La ciencia nos permitirá, parece decirnos la ilustrada Mary a través de su personaje Frankenstein, dominar lo que nos aterra pero que a la vez admiramos - como románticos - por sublime, la Naturaleza. Siguiendo la lógica adorniana la autora del Frankenstein también puede estar haciendo una analogía entre la Naturaleza y la Mujer. Lo Mujer es encasillado en la naturaleza, es aterrador y majestuoso, hasta tal punto que el progreso científico - con fuerte sesgo patriarcal — también pretende dominarlo. ¿Puede haber algo mejor para dominar a la mujer que arrebatarle la función reproductiva? ¿No es ese el objetivo final de Víctor Frankenstein al pretender infundir vida en la materia muerta?

El ilustrado Víctor Frankenstein, tras su primer impulso hacia lo científico y experimental, se adentra en la Universidad de Ingolstadt en la ciencia del momento, la filosofía natural. Uno de sus profesores de química, el profesor Waldman, hará un alegato a favor de la ciencia moderna frente a la superchería y la superstición que han abonado los estudios premodernos. Tal conferencia lo marcará significativamente. Las palabras del maestro son harto significativas:

Los antiguos maestros de esta ciencia prometieron cosas imposibles y nada consiguieron. Los maestros de la modernidad prometen muy poco; saben que no podemos transmutar los metales y que el elixir de la vida es una quimera. Sin embargo, estos filósofos, cuyas manos parecen destinadas a hurgar en la inmundicia y sus ojos a entregarse al microscopio o al crisol, han obrado milagros [...] Han ascendido a los cielos, han descubierto cómo circula la sangre y la naturaleza del aire que respiramos ${ }^{7}$.

Entrar en contacto con el profesor Waldman será otro de los acontecimientos «triviales» que decidirán el destino del joven Frankenstein. El lado romántico de la autora también está presente en la concepción o el sentido trágico de la vida que tiene su origen en sucesos triviales. Dos de estos sucesos marcan el destino de Víctor: la llegada de su prima Elizabeth para vivir con ellos y el citado alegato científico del profesor Waldman. La personalidad romántica y melancólica de Frankenstein es un buen ejemplo de cómo un espíritu melancólico describe cualquier acontecimiento de su vida, por banal o simple que nos pueda parecer, como si se tratara de un momento crucial que marcará su destino. El mundo romántico «expulsa todo lo accidental; la interpretación trágica de la vida lleva consigo una estética de la simplicidad»»; en el mundo de Víctor no cabe lo accidental.

En los años que pasa en la Universidad será un apasionado de la ciencia. El prurito hacia el conocimiento científico le conduce a nuestro ilustrado protagonista a mantener la desmesura, una actitud más romántica que ilustrada. Al igual que el Fausto de Goethe, Víctor siente una sed infinita de conocimiento, en este caso, el conocimiento científico se pondrá al servicio de la búsqueda del principio de la vida. El objetivo de nuestro protagonista será infundir vida en la materia muerta. La ansiedad y desmesura dirigen su trabajo:

7 Ibíd., p. 120.

8 Maulnier, T., Racine, Gallimard, París 1962, p. 76. 
Ahora me tiemblan las piernas y el recuerdo nubla mi mirada, pero en aquellos tiempos un impulso infatigable y casi frenético me impelía a seguir adelante; parecía que mi espíritu y mis sentidos solo existieran para aquél único propósito [...] Pasaron los meses de verano y yo seguía ocupado, en cuerpo y alma, en un único propósito. Fue la estación más hermosa del año [...] pero mis ojos eran insensibles a los encantos de la naturaleza. Y los mismos sentimientos que ofuscaban mis sentidos también propiciaron que olvidara a aquellos amigos ausentes que se hallaban a muchos kilómetros de distancia ${ }^{9}$.

La desmesura romántica será derrotada por la reflexión «ilustrada y moralista» de nuestro protagonista que no deja de tener un tinte feminista, pero como explicaré más adelante, en este pasaje - y en otros muchos de la novelase trasluce una ética del cuidado que permitiría ver en la obra de Mary Shelley rasgos de un feminismo de la diferencia. El texto es muy explícito:

El ser humano que quiera conseguir la perfección tiene que conservar siempre la mente serena y tranquila (la desmesura es mala consejera), y jamás permitir que la pasión o los deseos pasajeros perturben su serenidad. No creo que la búsqueda del conocimiento sea una excepción a la regla. Si el estudio al que nos dedicamos tiende a debilitar nuestros afectos y a destruir el gusto por los placeres sencillos [...] nuestra investigación sin duda será ilícita, es decir, inapropiada para la mente humana. Si siempre se cumpliera esta regla, si ningún hombre permitiera que cualquier objetivo interfiriera en la tranquilidad del cariño familiar (Víctor Frankenstein en su desmesura ha olvidado por completo a su familia), Grecia no habría sido reducida a la esclavitud, César habría conservado su Imperio, la colonización de América se habría realizado de forma más gradual y no se habrían destruido los imperios de México y Perú ${ }^{10}$.

¿El moralista Frankenstein nos está diciendo que si ciertos valores, asociados a la feminidad como el cuidado y el cariño familiar, no se doblegaran frente al ímpetu insaciable de conocimiento y/o progreso científico, podríamos haber reescrito la historia de la civilización occidental? Tal vez no nos lo esté diciendo el joven Frankenstein pero sí lo está insinuando la moralista y feminista Mary Shelley. Aceptar el lugar que ocupamos en el mundo es una de las lecciones aprendidas por el protagonista. La ciencia patriarcal le ha conducido, en su afán de arrebatar a la mujer su papel reproductivo, a la desgracia. Las palabras que dirige a Robert Walton no dejan lugar a dudas:

Aprenda, si no de mis consejos, al menos de mi ejemplo, lo peligroso que puede resultar adquirir el conocimiento, y que es más feliz el hombre que considera a su pueblo natal el mundo entero en lugar del que aspira a superar los límites establecidos por su propia naturaleza ${ }^{11}$.

\footnotetext{
9 Shelley, M., op. cit., pp. 127-128.

10 Ibíd., p. 129. Los paréntesis son míos.

11 Ibíd., pp. 125-126. La cursiva es mía.
} 
La desmesura científica que podría ser vista como un rasgo heredado del optimismo ilustrado, sobre manera de la Ilustración inglesa, se ve constantemente corregida en la obra de Mary Shelley. Será corregida tanto por elementos románticos, que enfatizan la idea de no sobrepasar los límites que nos ha impuesto una Naturaleza (podríamos pensar que hay una concepción esencialista de la naturaleza) tan aterradora como sublime, como por la concepción moral de la autora que parece subrayar, constantemente, la imposibilidad de un progreso científico sin progreso moral.

\section{ENTRE EL FEMINISMo DE LA IGUALDAD Y EL FEMINISMO ROMÁNTICO DE LA DIFERENCIA}

Si la Ilustración inglesa sobresale por su idiosincrasia científica, la francesa ha pasado a la Historia como baluarte de tres de los valores más importantes para construir cualquier teoría ética y política. Me refiero, evidentemente, a la libertad, la igualdad y la fraternidad (entendida hoy en día como solidaridad). Todo teórico ilustrado que se preciase debía presentar algún tipo de ensayo sobre uno de tales valores. Ni que decir tiene que, al igual que con la idea de progreso, no existía un consenso sobre el significado y la evolución de tales ideas, más bien lo que encontramos es un verdadero disenso.

El concepto de libertad en un ilustrado como Rousseau sigue preso de la concepción de los antiguos, a saber, es preciso concebir la libertad siempre al servicio de la polis. Su teoría política republicana exige tal caracterización. La república hace libres a sus ciudadanos, con esta forma política rompe Rousseau con la legitimación natural o teológica del poder. Será la voluntad de los ciudadanos la que legitime el poder. Ahora bien, esa voluntad se expresa como voluntad general. La voluntad general rousseaniana no es la suma de las voluntades libres de cada ciudadano. Está unida a una comunidad ligada a una tradición, a una sangre y a una tierra.

En la novela de Mary Shelley no se ve reflejado este concepto de libertad; sería excesivamente forzado. El concepto de libertad que se ve más claramente es la llamada libertad de los modernos: una libertad que conduce al sujeto a disfrutar de sus derechos.

En este apartado me centraré en la idea de igualdad. En el desarrollo de tal idea quedan reflejadas gran parte de las contradicciones y paradojas del pensamiento ilustrado. La madre de Mary Shelley, Mary Wollstonecraft, denunció en Vindicación de los derechos de la mujer tales abusos del concepto. La igualdad sólo se daba entre iguales, he ahí la paradoja. Todo lo desconocido, todo lo que provocaba terror, era necesario someterlo. De este modo, Rousseau distingue claramente dos tipos de pacto: el pactum societatis y el pactum subiectonis. El primero es el pacto entre iguales que funda y legitima la aparición del Estado. Una vez que el hombre abandona el estado de naturaleza y firma el contrato social — pacto entre iguales-, la subordinación y la sujeción siguen presentes en la sociedad y en el mismo pacto. El más claro ejemplo de sujeción lo encuentra 
Rousseau en la subordinación de la mujer al varón tras el contrato sexual presente en el propio pacto originario. Como explica Pateman:

La dominación de los varones sobre las mujeres y el derecho de los varones a disfrutar de un igual acceso sexual a las mujeres es uno de los puntos en la firma del pacto original. El contrato social es una historia de libertad, el contrato sexual es una historia de sujeción [...] la libertad de los varones y la sujeción de las mujeres se crea a través del contrato original [...] El pacto originario es tanto un pacto sexual como un contrato social, es sexual en el sentido de que es patriarcal —es decir, el contrato establece el derecho político de los varones sobre las mujeres-y también es sexual en el sentido de que establece un orden de acceso de los varones al cuerpo de las mujeres ${ }^{12}$.

La igualdad radical y universal, como valor de la Ilustración, no existe; en el caso de Rousseau esta encuentra un freno en la mujer. Existe la fratría masculina, que permite el pacto entre iguales, pero la separación natural de los sexos defendida por el pensador ginebrino sustenta, aunque pueda parecer paradójico, todo el orden social y político: «Rousseau sostiene que de haber "una base natural sobre la cuál asentar los vínculos convencionales" la base natural del matrimonio y de la familia [...] Para ser un buen esposo y un buen ciudadano un hombre debe tener una buena, digamos obediente, esposa, que mantenga el orden de la esfera que es el fundamento natural de la vida» ${ }^{13}$.

Este posicionamiento rousseauniano se ve claramente en su obra El Emilio (1762). Emilio será educado como individuo, que hará uso de su igualdad y responsabilidad, y como buen ciudadano; pero para alcanzar tal objetivo necesita a una buena compañera, Sofía. La educación dada a Sofía y explicada en el capítulo V no deja lugar a dudas, Sofía ha de ser educada como «ángel doméstico» con el fin de agradar y satisfacer todos los deseos y necesidades de su esposo. La esposa no puede poner en peligro el dominio conyugal del esposo, si lo hiciera la sociedad civil estaría en peligro. Rousseau llegará a afirmar que todo pueblo sucumbe por el desorden de las mujeres.

La mente lúcida de Mary Wollstonecraft criticará las contradicciones rousseaunianas que le alejan de una auténtica Ilustración universal y emancipatoria. Mostraré un texto para reforzar la imagen de una de las pensadoras ilustradas del XVIII:

Rousseau declara que una mujer nunca debe ni por un momento sentirse independiente, que debe regirse por el miedo a ejercitar su astucia natural y hacerse una esclava coqueta para volverse un objeto de deseo más atrayente, una compañía más dulce para el hombre cuando quiera relajarse [...] insinúa que verdad y fortaleza, las piedras angulares de toda virtud humana, deben cultivarse con ciertas restricciones, porque, con respecto al carácter femenino, la obediencia es la gran lección que debe inculcarse con vigor inflexible.

12 Pateman, C., El contrato sexual, Anthropos, Barcelona 1995, pp. 10-11.

13 Ibíd., p. 139. 
¡Qué disparate! ¿Cuándo surgirá un gran hombre con la suficiente fortaleza mental para soplar de encima los humos que el orgullo y la sensualidad han extendido sobre el tema? ${ }^{14}$

Los pensamientos y las obras de la madre eran bien conocidas por la hija; ahora bien, podríamos hacernos una pregunta central, ¿aparecen en el Frankenstein las ideas de un feminismo de la igualdad o de la Ilustración que pudo esbozar Mary Wollstonecraft en la Vindicación? Es evidente que Mary Shelley vivió en un entorno donde se fomentó la igualdad entre los sexos y donde la independencia era importante; más aún, ella practicó estos valores durante su existencia. Es cierto que el narrador de una novela no tiene porque reflejar los valores del autor. Hay una distancia literaria entre autor y narrador. Pero esta asunción no impide que en numerosas ocasiones, el autor utilice su narración para «educar»o «moralizar» a su público. En este caso, los valores de un feminismo de la igualdad no están muy presentes. Las dos figuras femeninas más importantes, desde el punto de vista narrativo, son Elizabeth y la hermana de Robert Walton, la señora Saville. La segunda de ellas no tiene personalidad propia; sabemos tan sólo que está casada y que es la hermana abnegada y preocupada por el espíritu aventurero de su hermano Robert. Un papel muy femenino en la línea rousseauniana. En cuanto a Elizabeth sabemos que es amada y admirada por Víctor, pero ¿posee cualidades virtuosas ligadas a su feminidad o son cualidades universales propias del varón y la mujer? A pesar de estar destinada a ser la esposa de Víctor, y a diferencia de la educación que debe recibir una mujer como Sofía, en la obra de Rousseau, totalmente diferente al varón, Elizabeth es educada junto a Víctor y por lo que nos dice el narrador es educada en los mismos estudios y maneras que el varón. No solo se convierte en la compañera de juegos de Víctor y en su amiga, sino que disfrutará como nadie de la libertad. A pesar de estos tintes emancipatorios e ilustrados, Elizabeth no tiene el afán de conocimiento de Víctor, no realiza estudios superiores, permanecerá siempre en casa, como una Penélope, esperando a Víctor. Incluso en la narración, el espíritu libre de Elizabeth se matiza: «Nadie era capaz de disfrutar de la libertad como ella, aunque también sabía someterse con infinita gracia a las normas y a las imposiciones $»^{15}$.

Sopesando el conjunto de la obra, para ser justos, no encontramos, en los personajes femeninos, una defensa o puesta en práctica del feminismo de la igualdad. No encontramos una mujer, que en el ejercicio de su libertad, emprenda una aventura intelectual o una aventura expedicionaria, por poner dos ejemplos de libertad que protagonizan Víctor y Robert, respectivamente. Todo lo contrario, ambos varones tienen a sendas mujeres esperándoles, a Elizabeth y a la señora de Saville.

14 Wollstonecraft, M., Vindicación de los derechos de la mujer, Cátedra, Madrid 1994, p. 137.

15 Shelley, M., op. cit., p. 108. 
El feminismo más claro presente en la obra de Mary Shelley es de corte romántico y esencialista. Me refiero a un feminismo de la diferencia.

Por un lado, en la obra de Mary Shelley podemos encontrar bastantes rasgos de la todavía potente sociedad patriarcal. El varón es el científico (Víctor) y el explorador (Robert), la mujer es la dulce esposa (Elizabeth) y la abnegada hermana (señora de Saville). El hombre sigue teniendo en sus manos el poder del conocimiento. Es él el personaje faústico. La mujer no tiene una tal naturaleza. En su desmesura faústica, tanto Víctor en su experimento como Robert en su expedición, llegarán al límite de lo razonable. Más aún, la propia criatura de Frankenstein, que no tiene identidad, tendrá sexo, será varón y se verá abocado, de igual modo que los demás protagonistas masculinos, a una sed de venganza y a una crueldad inagotable, faústica.

En este modelo patriarcal la «tecnociencia» se pone al servicio del sistema patriarcal. Al eclipsar el papel de la mujer como reproductora, el poder del varón se amplia hasta límites insospechados.

Por otro lado, la moralista hija de Mary Wollstonecraft y William Godwin no puede sin más, como autora, permitir una apología del modelo clásico del patriarcado. Remedia esta situación haciendo que todos sus personajes masculinos centrales se rediman y reconozcan su vida fallida.

Robert Walton volverá a Inglaterra sin cumplir su ambicioso objetivo; ¿la desmesura lo ha cegado como a Víctor Frankenstein? En estas palabras finales Robert reconoce su derrota:

No sé cómo terminará todo esto, mas preferiría morir que regresar avergonzado por no haber podido cumplir mi propósito. Temo, no obstante, que ese será mi destino [...] La suerte está echada. He accedido a regresar si no perecemos en el intento. Mis esperanzas han quedado destruidas [...] Regreso sin haber descubierto nada, decepcionado. Todo ha terminado. Regreso a Inglaterra $^{16}$.

Mientras que Víctor, en las postrimerías de su existencia, se redime ante la idea de morir y advierte a Robert de los peligros de la desmesura faústica:

Por lo demás, le puedo decir que, ahora que espero fallecer de un momento a otro, siento una felicidad que no experimentaba desde hacía años. La imagen de mis seres queridos se presenta ante mí y a sus brazos me encomiendo. ¡Adiós, Walton! Busque la satisfacción en la serenidad y evite la ambición, aunque solo se trate del inocente anhelo de destacar en el terreno de la ciencia y compartir la gloria de los descubridores [...] Yo mismo fui víctima de unas esperanzas que me abocaron a la destrucción ${ }^{17}$.

Víctor, al pretender ir más allá de lo que su naturaleza le permitía (su sexo masculino no le permite crear vida), se verá condenado como un nuevo Prometeo a un sufrimiento infinito que sólo podrá aliviar la muerte. El poder faústico varonil acaba siendo autodestructivo para el propio hombre. Frente a este

16 Ibíd., p. 320.

17 Ibíd., p. 323. 
poder insensible, la narración de Shelley está haciendo una constante apología de la mesura, la serenidad, el amor familiar, e incluso de una ética del cuidado, todo ello valores presentes en un feminismo de la diferencia.

Quisiera destacar un punto que subraya el carácter feminista ligado a una ética del cuidado de la obra de Mary Shelley: el valor de la vulnerabilidad. La moralista Shelley se recrea en mostrar la vulnerabilidad de todos sus personajes centrales. Revisemos algunos de ellos. Comienzo por Robert Walton. Su orgullo y prepotencia se vendrán abajo cuando se percata que como todo ser vulnerable está a expensas no sólo de factores naturales — como grandes tempestades o inmensas masas de hielo que le impiden navegar-, sino de factores sociales y humanos, a saber, él no está solo en su empresa, depende, y de ahí su otro tipo de vulnerabilidad, de los miedos, anhelos y preocupaciones de sus compañeros de travesía. Los miedos de los marineros a seguir una expedición temeraria, lo hacen vulnerable y le obligarán a abandonar su idea prometeica.

No percatarse de esta vulnerabilidad conduce a Víctor Frankenstein y a sus seres más queridos a la infelicidad y a la destrucción. Víctor no puede actuar como si fuese un titán de la ciencia que en su contexto de descubrimiento vive ajeno a los demás y a las consecuencias de su creación. Víctor tiene seres queridos, vive en sociedad y su creación interactuará en el mundo de los hombres, por tanto, el contexto de justificación se yuxtapone, como una constelación, al contexto de descubrimiento. Ese ha sido el error de Víctor, no darse cuenta de ese vínculo. Si uno atiende a tal vínculo, descubrimiento y justificación unidos, o lo que es lo mismo progreso científico y técnico unido a progreso moral, no podrá olvidar el sufrimiento que cualquier descubrimiento puede provocar en cualquier ser humano vulnerable.

El mismo Víctor, Elizabeth, el pequeño William, Justine y la propia criatura de Frankenstein son víctimas de la ceguera de Víctor que pretende escapar de algo de lo que no podemos escapar, la vulnerabilidad. Ni tan siquiera el monstruo escapa de ella. Su falta de identidad, sus monstruosas proporciones y su soledad son tres de sus características que lo hacen más vulnerable. ¿Cómo reacciona ante tal vulnerabilidad? Con odio y con la búsqueda de la venganza. Su creador no le ha dado identidad (nunca conocemos su nombre ni su linaje), lo ha creado con un físico aterrador, lo ha condenado a la soledad (le ha negado la creación de una compañera), en definitiva, como le recrimina la criatura a su creador, ha olvidado que él, como creador, tiene unas responsabilidades hacia su engendro. Las palabras del monstruo dirigidas a Víctor no dejan lugar a dudas:

La humanidad odia a los desgraciados (vulnerables). ¡Cuánto odio debo de inspirar yo, que soy el más miserable de todos los seres vivos! Y tú, mi creador, me detestas, desdeñas a tu criatura, a la que estás unido por unos vínculos que solo pueden disolverse con la muerte de uno de los dos [...] Cumple con tus deberes hacia mí y yo cumpliré contigo y con la humanidad. Si aceptas mis condiciones, os dejaré en paz a todos, pero si te niegas blandiré el puño de la muerte hasta saciarme con la sangre de los amigos que aún te quedan [...] (los reproches del monstruo continúan) ¿Acaso no he sufrido ya 
bastante para que pretendas todavía hacerme más desgraciado [...] yo era generoso y bueno; y la desgracia me convirtió en un monstruo. Devuélveme la felicidad y volveré a obrar con virtud ${ }^{18}$.

La vulnerabilidad puede ser vista como elemento catalizador de todos los personajes centrales de la novela de Mary Shelley. Y por lo tanto, me inclino a ver un feminismo de tintes más románticos que ilustrados.

Las interpretaciones feministas del Frankenstein pueden ser plurales, precisamente, por el carácter plural de elementos ilustrados y románticos que aparecen en la obra y en sus personajes.

El tecnofeminismo de Haraway —una de las últimas interpretaciones feministas- pretendió subvertir el terror que provoca el monstruo creado por Víctor. ¿Cómo lo consigue? Mostrando lo positivo de un monstruo que en realidad puede ser visto como un híbrido emancipador. La criatura no tiene identidad, pero bien pudiera ser «lo otro» frente al brillante varón; puede ser la criatura que rompa los límites entre la mujer y el varón; la categoría HombreHembra de la que habla Haraway ${ }^{19}$.

Desde mi punto de vista, aunque interesante, no deja de ser forzada la interpretación de Haraway. No podemos olvidar que el monstruo tiene sexo, es varón. Otra cosa cabría interpretar si la criatura de Víctor Frankenstein hubiese sido una mujer. ¿Hubiera dado menos miedo, habría actuado con la misma sed de venganza? En la Universidad de Texas en Dallas el nuevo prototipo de robot - K-Bot - tiene rostro humano femenino, a diferencia del primero que tenía rostro humano masculino. Como afirma Judy Wajcman «cabría interpretar la apariencia femenina del K-Bot como fruto de la intención de reducir la sensación de amenaza que las máquinas podrían transmitir a sus creadores humanos ${ }^{20}$. Esto es otro tema de discusión y tal vez de un intento de reescribir la historia no tanto de Frankenstein, sino de una nueva criatura con rostro de mujer.

\section{BIBLIOGRAFÍA}

Adorno, T. W., y Horkheimer, M. (1994). Dialéctica de la Ilustración. Madrid: Trotta.

Haraway, D. (1995). Ciencia, Cyborgs y mujeres. La reinvención de la naturaleza. Madrid: Cátedra.

Maulnier, T. (1962). Racine. París: Gallimard.

Pateman, C. (1995). El contrato sexual. Barcelona: Anthropos.

Rousseau, J. J. (2012). Discurso sobre las ciencias y las artes. Discurso sobre la desigualdad entre los hombres. Madrid: Alianza Editorial.

18 Ibíd., pp. 183-184.

19 Haraway, D., Ciencia, Cyborgs y mujeres. La reinvención de la naturaleza, Cátedra, Madrid 1995.

20 Wajcman, J., El tecnofeminismo, Cátedra, Madrid 2006, p. 174. 
Shapin, S., y Schaffer, S. (1985). Leviathan and the Air-Pump: Hobbes, Boyle and the Experimental Life. Princeton: Princeton University Press.

Shelley, M. (2015). Frankenstein, o el moderno Prometeo. Barcelona: Penguin Clásicos. Wajcman, J. (2006). El tecnofeminismo. Madrid: Cátedra.

Wollstonecraft, M. (1994). Vindicación de los derechos de la mujer. Madrid: Cátedra.

Universidad de Oviedo

Asunción Herrera Guevara

Departamento de Filosofía

aherrera@uniovi.es

[Artículo aprobado para publicación en enero de 2019] 